\title{
Age-structure, harvesting and climate effects on population growth of Arcto-boreal fish stocks
}

\author{
Joël M. Durant ${ }^{1, *}$, Dag Ø. Hjermann ${ }^{2}$ \\ ${ }^{1}$ Centre for Ecological and Evolutionary Synthesis (CEES), Department of Biosciences, \\ University of Oslo, PO Box 1066 Blindern, 0316 Oslo, Norway \\ ${ }^{2}$ Norwegian Institute for Water Research (NIVA), Gaustadalléen 21, 0349 Oslo, Norway
}

\begin{abstract}
We used a comparative approach investigating commercially fished species with contrasting life histories and trophic positions in an Arcto-boreal system, the Barents Sea. Our objective was to address the ecological consequences of harvesting on stock properties (stochastic growth rate; a property related to intrinsic growth rate) in relation to different external conditions (fishing pressure and climate). We used age-structured population matrices to calculate the transient elasticity of population growth with respect to recruitment (how much population growth depends on recruitment) over time. Using a generalized additive model (GAM) analysis, we found that the transient elasticity of population growth to recruitment overall depends mostly on age structure (which in turn is affected by fishing) but also on climate (temperature change or winter North Atlantic Oscillation). Our results indicate that under warmer conditions, population growth of high latitude stocks becomes increasingly dependent on recruitment, which makes the stocks more difficult to manage. In general, there was no effect of ongoing fishing pressure on elasticity after age structure had been taken into account, supporting the view that long-term fishing pressure affects the susceptibility of the population to climate indirectly, by changing the age structure of the stock. However, for most of the stocks we have studied here, populations have low elasticity to recruitment due to their life history, meaning that the health of the stock mainly depends on survival after the recruitment stage; i.e. fisheries management is more important than climate.
\end{abstract}

KEY WORDS: Fisheries effect Climate effect $\cdot$ Recruitment $\cdot$ Comparative analysis $\cdot$ Matrix model $\cdot$ Fish $\cdot$ Barents Sea $\cdot$ Management

\section{INTRODUCTION}

Recruitment variation is a major source of variability in the biomass of adult fish (Hjort 1914). If we ignore year-to-year recruitment variability, we would expect all organisms to have a semelparous life cycle (Cole 1954). However, Murphy (1968) and Schaffer (1974) have shown that the existence of iteroparous life histories - going against this prediction (Cole's paradox) - is the result of natural fluctuations that principally affect the immature individual's survival. Thus, year-to-year recruitment variability has a greater influence on short-lived species and a lesser

${ }^{*}$ Corresponding author: joel.durant@ibv.uio.no impact on long-lived species where the mature population typically consists of a larger number of cohorts (Stearns 1992). However, changes in life history parameters (survival and age of maturation) are also expected to change the population's sensitivity to year-to-year recruitment variability (Rogers et al. 2011, Hidalgo et al. 2012, Durant et al. 2013) as expected in harvested populations. In recent decades, the most conspicuous change is the large extra mortality exerted on exploited fish populations. For instance, fishing reduces the average life span of the stock, leading to a spawning stock which mostly consists of a few age classes, and thereby a closer link

() The authors 2017. Open Access under Creative Commons by Attribution Licence. Use, distribution and reproduction are unrestricted. Authors and original publication must be credited. 
between recruitment variation and the abundance of large fish (Ottersen 2008, Ottersen et al. 2013). Also, intensive fishing of sub-adult fish can lead to fisheries-induced evolution of decreased age at maturation (Jørgensen et al. 2007). However, changes in climate, predation and food availability also affect survival (Leggett \& Deblois 1994, Drinkwater et al. 2010) and age of maturation (Marshall \& McAdam 2007, Wright et al. 2014), and thereby the sensitivity of the population to recruitment variations.

The perpetuation of a fish population is affected by the variation of many factors (recruitment, fishing mortality, natural mortality, age at maturation; see e.g. Lambert 2013). These effects are conveniently integrated by the properties of the population's transition matrix (Caswell 2001) and affect the population growth (Wright 2014). One of the properties of the transition matrix is the elasticity of population growth with respect to each matrix element (i.e. reproduction and survival at different ages/stages). Elasticity analysis measures the relative change in population growth $\lambda$ caused by a proportional change in any of the matrix elements (de Kroon et al. 1986). Typically, elasticity is computed based on a single transition matrix, representing the mean transition matrix over a period of time, and capturing the intrinsic life history of the species as well as the mean effects of fishing. However, the population structure of sub-arctic fish populations is often in a constant state of flux due to huge variations in reproduction (caused by variations in climate and spawning stock) as well as variations in fishing pressure (including fishery closures), climate and abundance of predators and prey. Therefore, it can be useful to also investigate changes in elasticity over time (transient elasticity; Caswell 2007) based on each year's transition matrix. In a previous study, we compared the transient elasticity on transitory matrices among gadoid fishes that inhabit different environments and experience different fishing intensities (Durant et al. 2013).

The purpose of the present study is to investigate how external forcing (climate and fishing) and age structure affect the transient elasticity to recruitment for different key fish species which occupy different trophic levels in a single Arcto-boreal marine ecosystem, the Barents Sea. We did this by calculating the population growth based on annual Leslie matrices, and then modelled the associated transient elasticities (using generalized additive models) for 5 commercially exploited stocks: Northeast Arctic (NEA) cod Gadus morhua, NEA haddock Melanogrammus aeglefinus, capelin Mallotus villosus, polar cod Boreogadus saida and the Norwegian spring spawning (NSS) herring Clupea harengus. These species represent different levels of the food chain: capelin, herring and polar cod are pelagic, planktivorous fish and a crucial trophic link between zooplankton and top predators, while cod and haddock are demersal fish feeding on a mixed diet including fish and benthic animals (Jakobsen \& Ozhigin 2011). The population dynamics of these species is different due to inherent life history and fisheries differences, and perhaps also fisheries-induced evolution (see Fig. 1). Among these stocks, only the capelin and polar cod are semelparous, and our focus is not primarily on the evolved difference among species but on the effect of external forcing on their dynamics. The recruitment of these stocks varies substantially between years due to both climatic fluctuations and interspecific predation (Hamre 1994, Hjermann et al. 2004). We focus on the contribution of recruitment to population growth (hereafter elasticity to recruitment, or just elasticity), as elasticity to survival varies in concert with elasticity to recruitment (except in the opposite direction). This study will contribute to the understanding of sub-arctic commercial stocks that are also strongly affected by climate fluctuations and change.

\section{METHODS}

The fish data used (age-specific abundance, fishing mortality and mature proportion) were all extracted from fishery assessments reported by ICES (see Table 1). For 3 of the species (cod, haddock, herring), assessment is performed using virtual population analyses (VPA; see Lassen \& Medley 2001, Shepherd \& Pope 2002), i.e. based on commercial catch data with survey data used for error correction (tuning). For the remaining 2 (capelin and polar cod), assessment is mainly based on acoustic surveys combined with trawl sampling (see Table 1 for references). Two climatic variables were used as potential environmental drivers: the North Atlantic Oscillation (NAO), calculated for the winter months (wNAO; Hurrell \& Deser 2009), and the annual average sea temperature (ST) measured monthly along the Russian Kola meridian transect $\left(70^{\circ} 30^{\prime}\right.$ to $72^{\circ} 30^{\prime} \mathrm{N}$, $\left.33^{\circ} 30^{\prime} \mathrm{E}\right)$. We used vertically averaged data collected at 5 stations on the Kola section at the standard depths: 1, 10, 20, 30, 50, 75, 100, 150 and $200 \mathrm{~m}$. A summary of the sources of the data used is provided in Table 1. More information on the 5 stocks studied (diet, distribution and fishing) can be found in Jakobsen \& Ozhigin (2011). 
Table 1. Data description of the stocks considered: Northeast Arctic (NEA) cod Gadus morhua, Norwegian spring spawning (NSS) herring Clupea harengus, NEA haddock Melanogrammus aeglefinus, capelin Mallotus villosus and polar cod Boreogadus saida. Period: maximum period covered by the data (parentheses: years used for different GAM analyses). Because virtual population analysis (VPA) data are not reliable in the later years, we used a shorter time series than was available. The calculation method for transient elasticity further reduces the length of the time series

\begin{tabular}{|c|c|c|c|}
\hline Stock & Period & Data & Source (see footnotes for references) \\
\hline \multirow[t]{4}{*}{ NEA $\operatorname{cod}^{\mathrm{a}}$} & 1946-2012 (1946-2002) & Fishing mortality $\left(F_{5-10}\right)$ & Table $3.24 \mathrm{a}, \mathrm{p} 195$ \\
\hline & & Maturity at age (\%) & Table 3.10, p 168 \\
\hline & & Weight at age (kg) & Table 3.7, p 163 \\
\hline & & Number at age $\left(10^{3}\right)$ & Table 3.21, p 189 \\
\hline \multirow[t]{4}{*}{ NEA haddock ${ }^{a}$} & 1950-2012 (1950-2003) & Fishing mortality $\left(F_{4-7}\right)$ & Table 4.18, p 275 \\
\hline & & Maturity at age (\%) & Table 4.8, p 260 \\
\hline & & Weight at age (kg) & Table 4.6, p 259 \\
\hline & & Number at age $\left(10^{3}\right)$ & Table 4.14, p 271 \\
\hline \multirow[t]{4}{*}{ NSS herring } & 1950-2012 (1950-2005) & Fishing mortality $\left(F_{5-14}\right)$ & Table 3.4.3, p 68 ${ }^{\mathrm{b}}+$ Table 7.7.3.3.3, p 387 \\
\hline & & Maturity at age (\%) & Table 7.7.5.1, p 382 \\
\hline & & Weight at age (kg) & Table 7.5 .4 .2$, p $375^{\mathrm{c}}$ \\
\hline & & Number at age $\left(10^{9}\right)$ & Table 3.4.1, p 64 ${ }^{\mathrm{b}}+$ Table 7.7.3.3.1, p 385 \\
\hline \multirow[t]{4}{*}{ Capelin $^{\mathrm{a}}$} & $1974-2009$ (1974-2006) & Fishing mortality & $F_{t}=-\ln \left(1-\right.$ Landing $_{t} /$ Biomass $\left._{t-1}\right) ;$ Table 9.6, p 530 \\
\hline & & Maturity at age (\%) & $\begin{array}{l}\text { Calculated from Table 9.3, p } 527 \text { (mature if length } \geq \\
14.5 \mathrm{~cm} \text { ), and older ICES AFWG reports }\end{array}$ \\
\hline & & Weight at age $(\mathrm{kg})$ & $\begin{array}{l}\text { Calculated from Table 9.3, p 527, and older ICES } \\
\text { AFWG reports }\end{array}$ \\
\hline & & Number at age $\left(10^{9}\right)$ & Table 9.5, p 529 \\
\hline \multirow[t]{6}{*}{ Polar cod ${ }^{d}$} & 1986-2012 (1946-2009) & Fishing mortality & $\begin{array}{l}F_{t}=-\ln \left(1-\text { Landing }_{t} / \text { Biomass }_{t-1}\right) \text { with catch data } \\
\text { from www.ices.dk and biomass; Table 5.2.2.2, p } 54\end{array}$ \\
\hline & & Maturity at age (\%) & $\begin{array}{l}\text { Calculated from Table 5.2.2.1, p } 53 \text { (mature if length } \\
\geq 15 \mathrm{~cm} \text { ) }\end{array}$ \\
\hline & & Weight at age (kg) & Table 5.2.2.2, p 54 \\
\hline & & Number at age $\left(10^{6}\right)$ & Table 5.2.2.2, p 54 \\
\hline & $1921-2012$ & $\mathrm{ST}^{\mathrm{e}}\left({ }^{\circ} \mathrm{C}\right)$ & $\begin{array}{l}\text { Mean Barents Sea }(\mathrm{BS}) \text { temperature calculated from } \\
\text { monthly mean temperatures, } \mathrm{Jan}_{t} \text { to } \mathrm{Dec}_{t} \text {, at } 0-200 \mathrm{~m} \\
\text { depth in Atlantic water parts of the Kola section } \\
\left(70.5-72.5^{\circ} \mathrm{N}, 33.5^{\circ} \mathrm{E}\right) \text { during } 1921-2013\end{array}$ \\
\hline & $1864-2012$ & $w N A O^{f}$ & $\begin{array}{l}\text { Station-based winter }\left(\mathrm{Dec}_{t-1}-\mathrm{March}_{t}\right) \text { North Atlantic } \\
\text { Oscillation index }\end{array}$ \\
\hline
\end{tabular}

\section{Calculation of population growth and elasticity}

We investigated the population dynamics implications of fishing, climate and population structure on Barents Sea populations by calculating the relative contribution (i.e. elasticity) of the reproductive rates to changes in population growth $(r)$. We compiled annual age-structured transition matrices $\mathbf{A}_{t}$ for each population studied (Leslie 1945, Caswell 2001). Note that $\mathbf{A}_{t}$ is compiled for the age structure measured in year $t$ (hence valid only for the time frame year $t$ to year $t+1$ ), as is the resulting annual realized population growth rate, $r_{t}$, here defined as $\ln$ (Dominant eigenvalue of $\mathbf{A}_{t}$ ). The transition (Leslie) matrix $\mathbf{A}_{t}$ summarizes the dynamics of the populations between time $t$ and time $t+1$. The fundamental relationship of age-structured matrix models is given by $\mathbf{n}_{t+1}=\mathbf{A}_{t} \mathbf{n}_{t}$, where $\mathbf{n}_{t}$ is a vector representing the number of individuals for each age class at time $t$. 
For a given year, the transition matrix $\mathbf{A}_{t}$ is defined as follows:

$$
\begin{aligned}
\mathbf{A}_{t} & =\left\{\begin{array}{ccccc}
\mathrm{RS}_{0, t} & \mathrm{RS}_{1, t} & \mathrm{RS}_{2, t} & \ldots & \mathrm{RS}_{i \max , t} \\
S_{1-0, t} & 0 & 0 & \ldots & 0 \\
0 & S_{2-1, t} & 0 & \ldots & 0 \\
\ldots & \ldots & \ldots & \ldots & \ldots \\
0 & 0 & 0 & S_{i \max -(i \max -1), t} & 0
\end{array}\right\} \\
& =\left\{\begin{array}{ccccc}
F_{1, t} & F_{2, t} & F_{3, t} & \ldots & F_{\max , t} \\
P_{1-0, t} & \ldots & \ldots & \ldots & \ldots \\
\ldots & P_{2-1, t} & \ldots & \ldots & \ldots \\
\ldots & \ldots & \ldots & \ldots & \ldots \\
\ldots & \ldots & \ldots & P_{\max -(i \max -1), t} & \ldots
\end{array}\right\}
\end{aligned}
$$

where $P_{i-(i-1), t}$ (i.e. $S_{i-(i-1), t}$ ) is the survival between age-class $i$ at year $t$ and age-class $i-1$ at year $t-1$, and $\mathrm{RS}_{i, t}$ is the recruitment success of the year-class $i$ at year $t$. $F_{i, t}\left(\right.$ i.e. $\left.\mathrm{RS}_{i, t}\right)$ is function of 2 components: the maturity rates and the number of survived recruits per mature fish.

In order to evaluate how recruitment affects spawning stock biomass and population numbers, we performed an analysis of transient elasticity to recruitment variation (hereafter called elasticity $\boldsymbol{e}_{;} \boldsymbol{e}$ being the contribution of recruitment or survival to population growth changes) following the principles defined by Caswell (2007) and methods described by Durant et al. (2013). We used numerical methods based on simulating the population from year $t$ to year $t+t_{\mathrm{g}}$. We selected $t_{\mathrm{g}}$ to be approximately equal to the mean of the year-specific generation time $\mu_{t}$ (the mean age of the parents of the offspring produced by a cohort over its lifetime, Caswell 2001). The annual generation time $\mu_{t}$ (which changes from year to year), is calculated from $\mathbf{A}_{t}$ and defined as follows:

$$
\mu_{t}=\frac{\sum_{i} i\left(\prod_{j=1}^{i-1} P_{j, t}\right) F_{i, t}}{\sum_{i}\left(\prod_{j=1}^{i-1} P_{j, t}\right) F_{i, t}}
$$

where we define $\prod_{j=1}^{0} P_{j, t}=1$.

Thus, changes in recruitment at time $t$ will have time to be reflected in the mature population at time $t+t_{\mathrm{g}}$. To calculate the transient elasticity we increased recruitment (i.e. the top-row elements of $\mathbf{A}_{t}$ ) by $1 \%$ in a single year $t$ and simulated population development for the next $t_{\mathrm{g}}$ years. Using a bootstrap procedure (100 replicates with a perturbation randomly selected from a uniform distribution ranging from -20 to $+20 \%$ ) we checked that the chosen $1 \%$ level of perturbation did not affect the results of the generalized additive model (GAM) analyses (see 'Statistical analysis'). Annual transient elasticity was then calculated as $\boldsymbol{e}_{t}=N^{\text {incr }}{ }_{(t+\operatorname{tg})} / N_{(t+\operatorname{tg})}-1$, where $N_{(t+t g)}$ is the number of fish in the age classes exploited by fishing in year $t+t_{g}$, and $N_{(t+t g)}^{\text {incr }}$ is the same quantity for the simulated case with increased recruitment in year $t$. This was repeated for every year $t$ of the time series (except those that are $<t_{\mathrm{g}}$ years from the end of the time series).

\section{Statistical analysis}

To investigate the effect of climate, anthropogenic pressure and the intrinsic demography in shaping elasticity to recruitment of the stocks, we combined stock-specific analyses with analyses across all the stocks. We related the temporal variability in elasticity to recruitment $\boldsymbol{e}$ of each stock to demographic variables such as fishing mortality and mean age of the spawning stock, as well as to the specific environmental variables of each stock (both regional and large-scale climate indices) using GAMs, via the mgcv library in R 2.14.1 (Wood \& Augustin 2002, R Development Core Team 2011). The rationale for also looking at the effect of environmental variables, which only indirectly affect $\boldsymbol{e}_{\text {, is that these variables }}$ may influence several demographic variables simultaneously, including recruitment and age of maturity. GAM is a modelling technique which can be thought of as a generalization of ordinary multiple regression, where there may be both linear and non-linear (smooth) effects of each explanatory variable (Wood \& Augustin 2002). The GAM procedure automatically selects the degree of smoothing based on the generalized cross validation (GCV) score. GCV is a proxy for the model's predictive performance. However, to avoid spurious and ecologically implausible relationships, we constrained the model to contain at maximum quadratic relationships, i.e. we set the maximum degrees of freedom to 2 for each smooth term (i.e. $k=3$ in the GAM formulation).

We ran 2 sets of analyses: (1) GAM analyses of each stock e separately, and (2) GAMM (generalized additive mixed model) analyses of all stock $\boldsymbol{e}$ values simultaneously, with stock as a random variable. In both cases, we wanted a parsimonious model which described the response well but was as simple as possible. We entered all candidate explanatory variables in the GAM/GAMM model and conducted model selection using shrinkage. In the shrinkage approach to model selection, the smoother is modified so it allows insignificant variables to be shrunk to zero (i.e. effec- 
tively removed) as part of the smoothness selection (Wood 2006). Thus, a reasonably optimal model is selected in a single step (i.e. the model that includes all of the terms that were not shrunk to zero). We used thin plate regression splines as smoothers. There was no temporal autocorrelation (using autocorrelation function $\mathrm{ACF}$ ) in the residuals of the models. Note that for both analyses, e was logit-transformed (ln $[\boldsymbol{e} /\{1-\boldsymbol{e}\}])$ to take into account the overdispersion in the residuals observed for 1 model.

\section{RESULTS}

Changes in abundance, generation time $\mu$, fishing mortality, population growth $r$ and transient elasticity to recruitment $\boldsymbol{e}$ over time are displayed for each stock in Fig. 1. All stocks have gone through considerable variations in abundance, including periods of very low abundance (even collapse for herring). Transient elasticity to recruitment $\boldsymbol{e}$ was on average lowest for NEA cod and highest for polar cod and
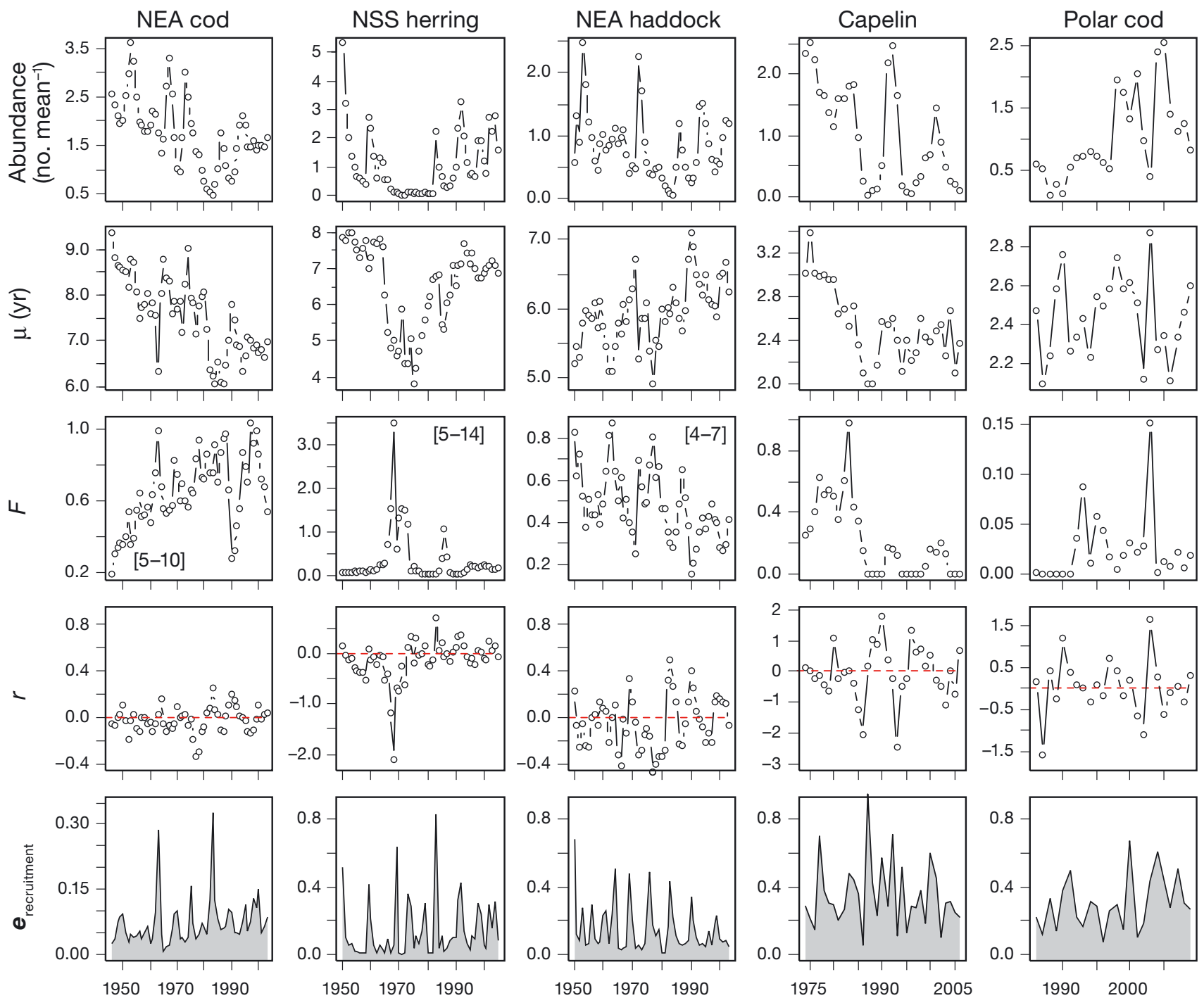

Fig. 1. Time series for the 5 Barents Sea fish populations used in the study: Northeast Arctic (NEA) cod Gadus morhua, Norwegian spring spawning (NSS) herring Clupea harengus, NEA haddock Melanogrammus aeglefinus, capelin Mallotus villosus and polar cod Boreogadus saida. The first row shows the change in the population abundance in numbers rescaled by dividing by the mean over time. The second row shows the generation time $\mu$ : the changes of the mean age of the parents of the offspring produced by a cohort over its lifetime with time. The third row shows the changes in fishing mortality $(F)$, with age range (yr) in square brackets when applicable (as reported in the data source, see Table 1). The fourth row shows the changes in the realized population growth rate with time $r$. The fifth row shows the changes in the relative importance of the transient elasticity to recruitment (e $\left.\boldsymbol{e}_{\text {recruitment }}\right)$ of the population growth rate with time. The matrices depend on recruitment and survival only, which means that $\boldsymbol{e}_{\text {recruitment }}=$ $1-\boldsymbol{e}_{\text {survival. }}$ Hence, if $\boldsymbol{e}_{\text {recruitment }}$ is small $(<0.5)$ then $\boldsymbol{e}_{\text {survival }}$ is necessarily high. Note the differences in axis scales 
capelin: $0.07 \pm 0.06$ (mean $\pm \mathrm{SD}$ ) (range 0.01-0.33) for NEA cod, $0.15 \pm 0.15(0.01-0.69)$ for NEA haddock, $0.14 \pm 0.17(0.00-0.83)$ for NSS herring, $0.30 \pm 0.16$ (0.08-0.67) for polar cod and $0.33 \pm 0.19(0.05-0.95)$ for capelin (Fig. 1).

Table 2 and Fig. 2 display the best stock-specific GAM models (selected by shrinkage) explaining the year to year change in the elasticity to recruitment $\boldsymbol{e}$. No explanatory variables were found to affect elasticity in the case of the capelin stock (in this instance, we also tried to use cod and herring abundance as explanatory variables, with no success). The explained proportion of the variance ranged from $29 \%$ for NEA haddock to $61 \%$ for NSS herring (Table 2). A decrease in the stock generation time $\mu$ led to an increase in $\boldsymbol{e}$ for the NEA cod, NEA haddock and NSS herring stocks. Note that polar cod had a tendency for the opposite relationship: low values of $\mu$ were associated with low values of $\boldsymbol{e}$. However, this effect was statistically uncertain $(p>0.05)$ and relatively weak. An increase in the fishing mortality $F$ led to an increase in $\boldsymbol{e}$ for the NEA cod stock only (note that cod is the stock with the overall highest $F$ ). For all stocks, e was positively related to warm conditions, i.e. high ST/wNAO (wNAO is positively related to ST). Note that only NSS herring e was not directly affected by ST but by wNAO (the herring is the only studied stock that lives its adult life outside the Barents Sea). An increase in abundance for the NEA cod and the NEA haddock stocks, and a decrease for the NSS herring stock, led to a decrease in $\boldsymbol{e}$.

Table 2 and Fig. 3 display the best GAMM model explaining transient elasticity of recruitment $\boldsymbol{e}$ across all fish stocks. In this case, the best model showed that a decrease in $\mu$ (Fig. 3A), an increase in ST (Fig. 3C) and an increase in the abundance of the stock (Fig. 3D) lead to an increase in $\boldsymbol{e}$. There was no significant effect of fishing mortality (Fig. 3B).

Looking at average values per stock (Fig. 3E,F,G), $\boldsymbol{e}$ was strongly negatively related to the generation time of the stock ( $\mu$ averaged over time) (Fig. 3E). The stocks displaying smaller average $\mu$ also displayed a

Table 2. GAM models on transient elasticity to recruitment of the population growth for Northeast Arctic (NEA) cod Gadus morhua, Norwegian spring spawning (NSS) herring Clupea harengus, NEA haddock Melanogrammus aeglefinus and polar cod Boreogadus saida. $s(X$, edf $=y)$ is the smoothing term, where $X$ represents the explanatory variable and $y$ is the estimated degrees of freedom (edf) of the smoothing term. When edf is 1 , the relationship is linear. The general sense of the relationship is indicated underneath with $(+)$ and $(-)$ or $(-/+)$ for quadratic relationships. Significance: ${ }^{*} p<0.05,{ }^{* *} p<0.01,{ }^{* * *} p<0.001$. i: intercept; $\mu$ : mean age of the parents of the offspring produced by a cohort over its lifetime (generation time); F: fishing mortality for different age ranges (indicated by subscripts); wNAO: winter North Atlantic Oscillation; ST: sea temperature at 0 to $200 \mathrm{~m}$ depth

\begin{tabular}{|c|c|c|c|c|c|c|c|}
\hline & Intercept & $\begin{array}{c}\text { Generation } \\
\text { time }\end{array}$ & $\begin{array}{l}\text { Fishing } \\
\text { mortality }\end{array}$ & wNAO & $\begin{array}{c}\text { Sea } \\
\text { temperature }\end{array}$ & Abundance & $\mathrm{R}^{2}$ \\
\hline NEA cod & $\begin{array}{c}\mathrm{i}^{* * *} \\
-2.75 \pm 0.08\end{array}$ & $\begin{array}{c}\mu^{*} \\
\text { edf }=0.58 \\
(-)\end{array}$ & $\begin{array}{c}F_{5-10^{*}} \\
\text { edf }=1.61 \\
(+)\end{array}$ & & $\begin{array}{c}\mathrm{ST}^{* *} \\
\text { edf }=0.87 \\
(+)\end{array}$ & $\begin{array}{c}\text { Abund* } \\
\text { edf }=0.67 \\
(-)\end{array}$ & 0.37 \\
\hline NSS herring $^{\mathrm{a}}$ & $\begin{array}{c}\mathrm{i}^{* * *} \\
-2.59 \pm 0.14\end{array}$ & $\begin{array}{c}\mu^{* * *} \\
\text { edf }=1.44 \\
(-)\end{array}$ & & $\begin{array}{c}\text { wNAO } \\
\text { edf }=1.43 \\
(+)\end{array}$ & & $\begin{array}{c}\text { Abund } * * * \\
\text { edf }=1.56 \\
\quad(+)\end{array}$ & 0.61 \\
\hline NEA haddock ${ }^{\mathrm{b}}$ & $\begin{array}{c}\mathrm{i}^{* * *} \\
-2.13 \pm 0.13\end{array}$ & $\begin{array}{c}\mu^{* *} \\
\text { edf }=1.17 \\
(-)\end{array}$ & & & $\begin{array}{c}\mathrm{ST}^{* * *} \\
\mathrm{edf}=0.98 \\
(+)\end{array}$ & $\begin{array}{c}\text { Abund }{ }^{* *} \\
\text { edf }=0.95 \\
(-)\end{array}$ & 0.29 \\
\hline Polar $\operatorname{cod}^{\mathrm{c}}$ & $\begin{array}{c}\mathrm{i}^{* * *} \\
-0.89 \pm 0.12\end{array}$ & $\begin{array}{c}\mu \\
\text { edf }=0.56 \\
(+)\end{array}$ & & $\begin{array}{c}\mathrm{wNAO}^{*} \\
\mathrm{edf}=1.91 \\
(-/+)\end{array}$ & $\begin{array}{c}\mathrm{ST}^{* *} \\
\mathrm{edf}=1.77 \\
(+)\end{array}$ & & 0.41 \\
\hline All stocks ${ }^{d}$ & $\begin{array}{c}\mathrm{i}^{* * *} \\
-2.03 \pm 0.07\end{array}$ & $\begin{array}{c}\mu * * * \\
\text { edf }=1.64 \\
(-)\end{array}$ & & & $\begin{array}{c}\mathrm{ST}^{* *} \\
\mathrm{edf}=0.97 \\
(+)\end{array}$ & $\begin{array}{c}\text { Abund } * * * \\
\text { edf }=0.99 \\
(+)\end{array}$ & 0.40 \\
\hline \multicolumn{8}{|c|}{$\begin{array}{l}\text { a } 1996 \text { was removed from the analysis being a highly influential outlier } \\
\text { b1953 and } 1972 \text { were removed from the analysis, being highly influential outliers } \\
\text { cYears with } F>1 \text { (1967-1968 and } 1970-1973) \text { were removed from the analysis, since they correspond to years of extreme } \\
\text { overfishing. } 1950 \text { and } 1969 \text { were also removed, being highly influential outliers } \\
\text { d Results of a GAMM model of transient elasticity for all stocks, with stock as random variable }\end{array}$} \\
\hline
\end{tabular}



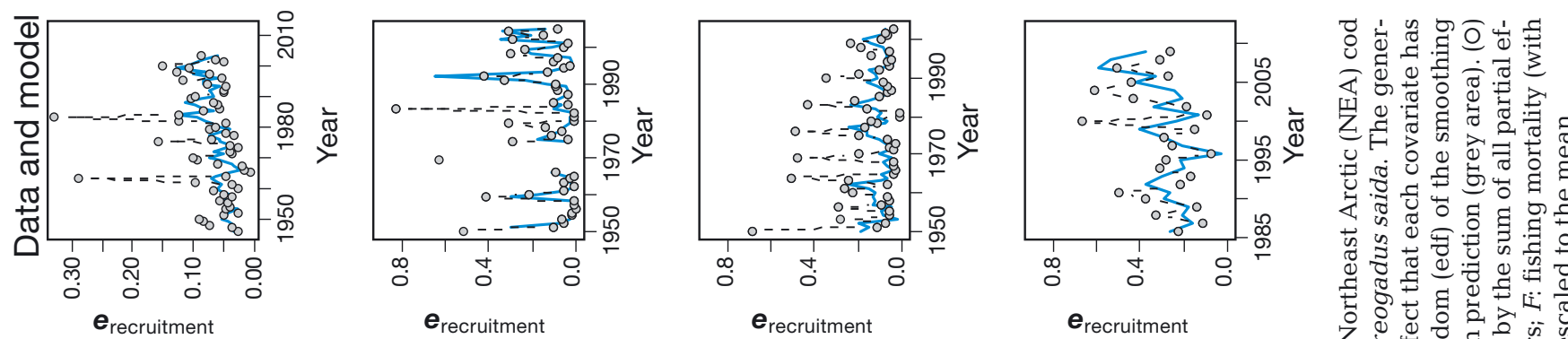

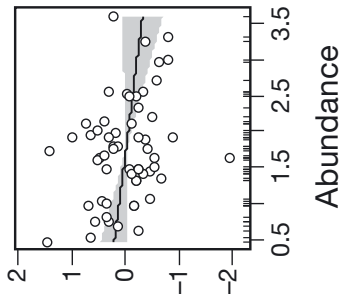

s(Abundance, 0.67)
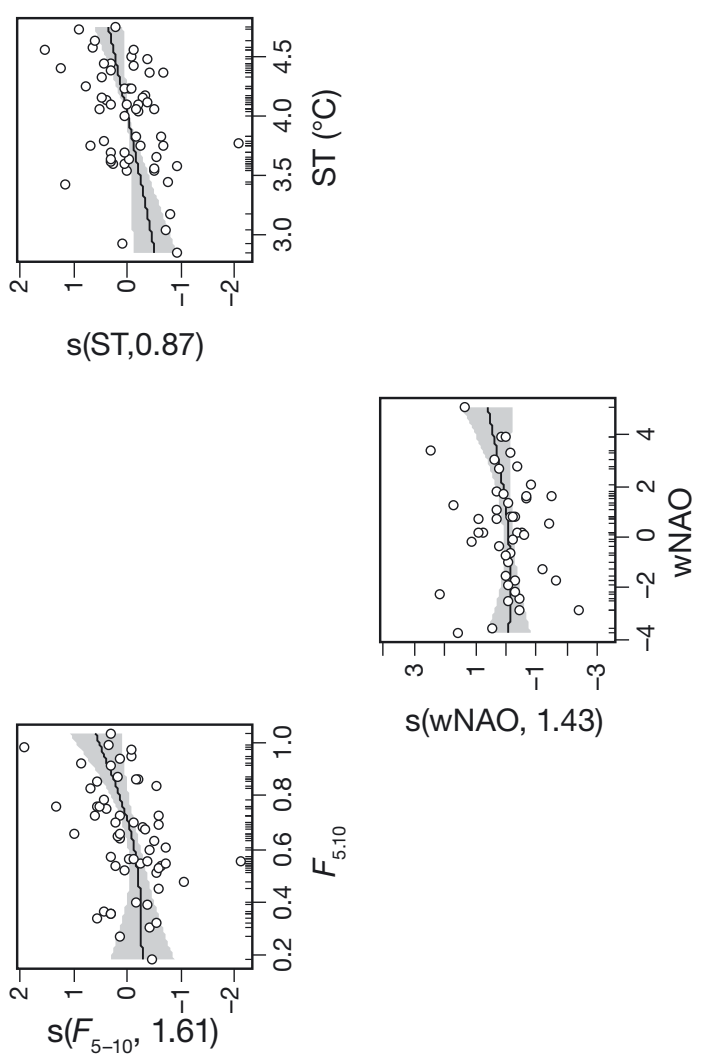

$\mathrm{s}(\mathrm{WNAO}, 1.43)$

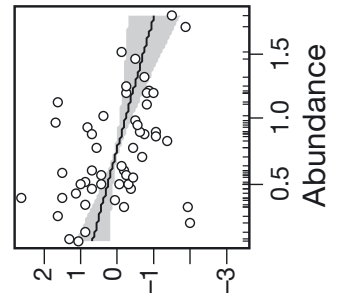

s(Abundance, 0.95)

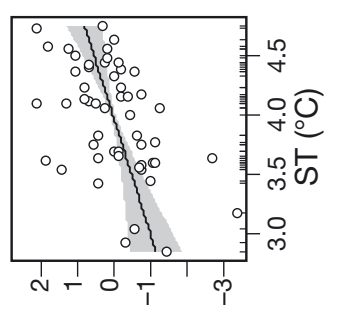

s(ST, 0.98)
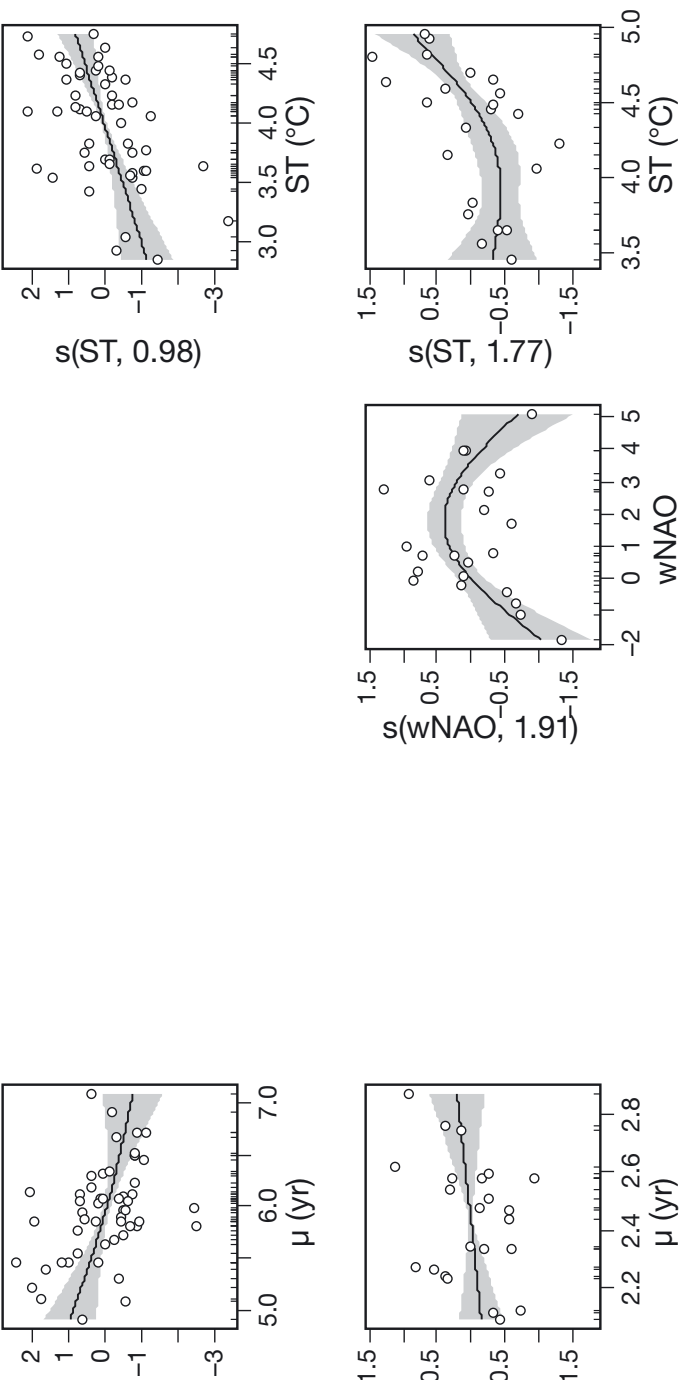

$s(\mu, 1.17)$

NEA haddock

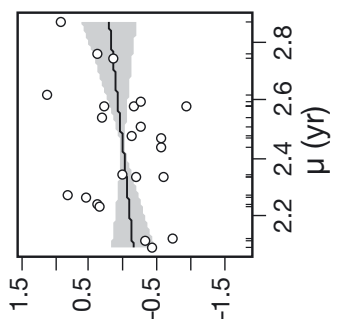

$\mathrm{s}(\mu, 0.56)$

Polar cod

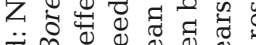

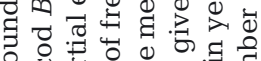

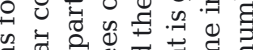

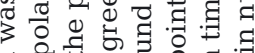

व) क्ष

द्व

ช

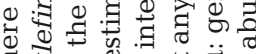
क人

ฯ ซ

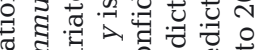

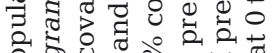

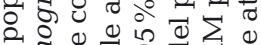

ปี

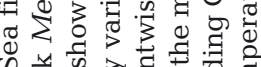

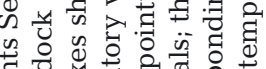

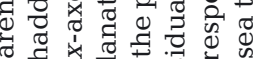

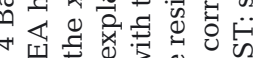

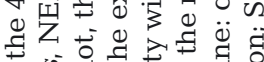

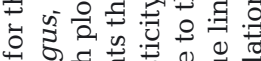

๑ ฐ

ฮี ธี

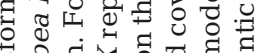

पू.

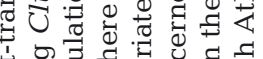

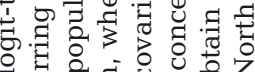

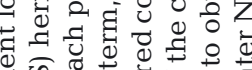

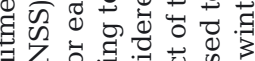

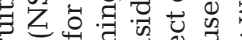

प्ष

을 范

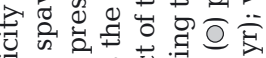

जि 웜

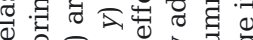

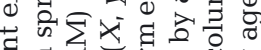

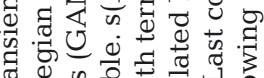

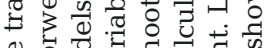

돈

प

क्ञ

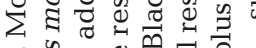

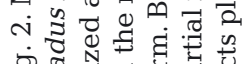

NEA cod
NSS herring 

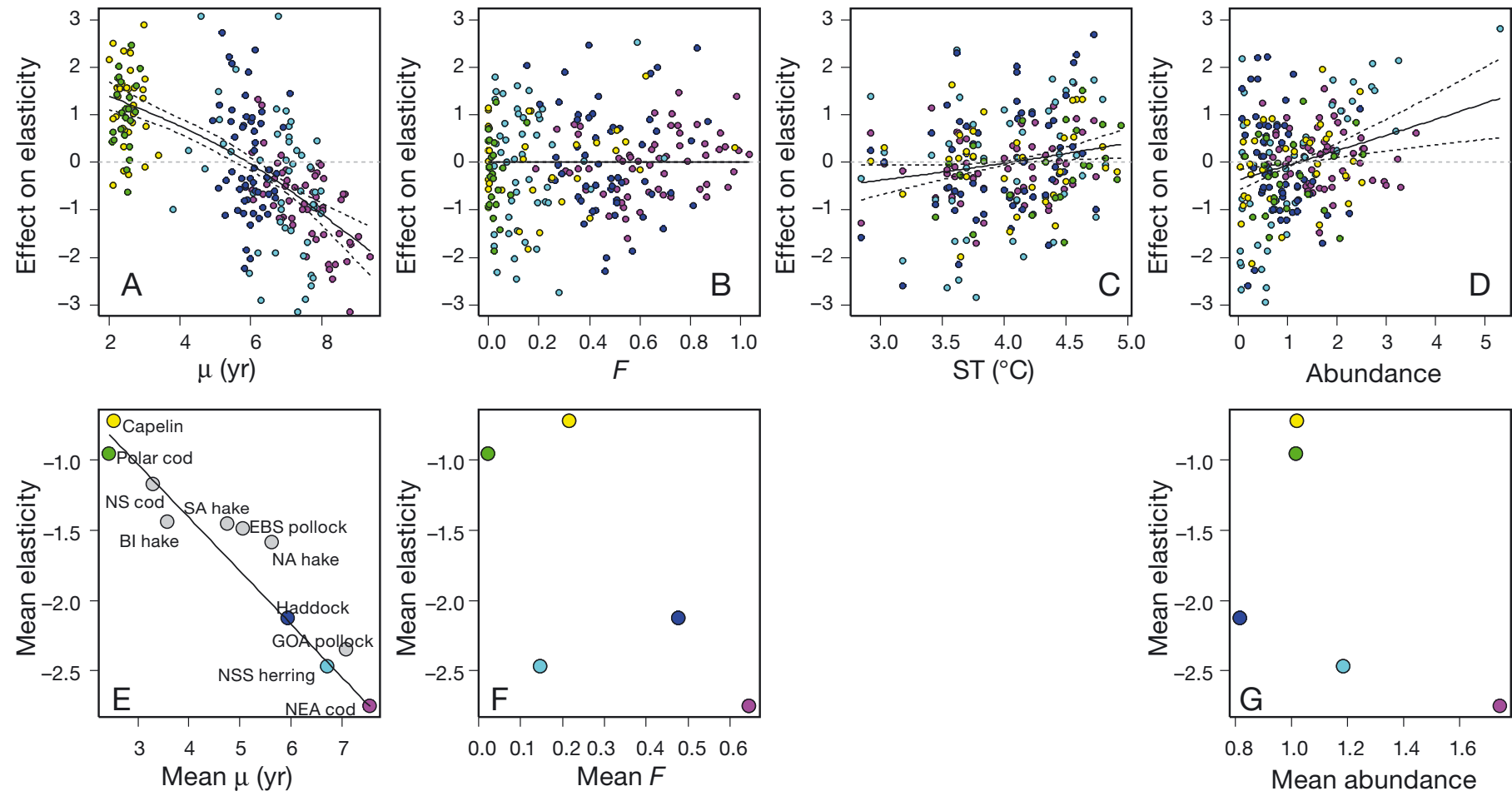

Fig. 3. (A) Relationship between mean age of the parents of the offspring produced by a cohort over its lifetime (generation time, $\mu$ ) and the contribution of recruitment to population growth rate (transient elasticity to recruitment $\boldsymbol{e}$ ). (B) Relationship between fishing mortality $F$ and logit-transformed $\boldsymbol{e}$. (C) Relationship between sea temperature (ST in ${ }^{\circ} \mathrm{C}$ ) and logit-transformed $\boldsymbol{e}$. (D) Relationship between the stock abundance and the logit-transformed e. Lines in (A-D): relationship found by the generalized mixed-effect model (GAMM); dotted lines: confidence intervals. See (E) for colour-coded stock names. (E) Relationship between mean $\mu$ and mean logit-transformed $\boldsymbol{e}$ for each stock. Solid line indicates the relationship (slope $=-0.37 \pm$ 0.02, p < 0.001); (O) results from Durant et al. (2013). (F) Relationship between mean fishing mortality $F$ and mean logit-transformed $\boldsymbol{e}$ for each stock. (G) Relationship between mean stock abundance and mean logit-transformed $\boldsymbol{e}$ for each stock. Northeast Arctic (NEA) cod Gadus morhua, Norwegian spring spawning (NSS) herring Clupea harengus, NEA haddock Melanogrammus aeglefinus, capelin Mallotus villosus and polar cod Boreogadus saida are from this study. Eastern Bering Sea (EBS) and Gulf of Alaska (GOA) pollock Theragra chalcogramma stocks, North Sea (NS) cod stock, northern Atlantic (NA), southern Atlantic (SA) and Balearic Islands (BI) hake Merluccius merluccius stocks are from Durant et al. (2013)

greater mean $\boldsymbol{e}$ (linear model, logit-transformed $\boldsymbol{e}=$ $0.07-0.34 \times \mu, F_{1,3}=371.9, \mathrm{p}<0.001, \mathrm{R}^{2}=0.98$ ), as population growth rate depended more on recruitment for stocks with less mature age classes. However, mean $\boldsymbol{e}$ was not related to mean fishing mortality $F$ (Fig. $3 \mathrm{~F}_{;} F_{1,3}=2.319, \mathrm{p}=0.23, \mathrm{R}^{2}=0.25$ ) or stock abundance (Fig. $3 \mathrm{G}_{;} F_{1,3}=0.324, \mathrm{p}=0.32, \mathrm{R}^{2}=0.10$ ).

\section{DISCUSSION}

In this study, we characterized the sensitivity of predicted population growth rate to modelled 1-time recruitment events. This provided insight into the relative importance of changes in recruitment to population growth in 5 of the most (ecologically and commercially) important stocks in the Barents Sea (Jakobsen \& Ozhigin 2011). NEA cod, NEA haddock and capelin are the principal commercial species in the Barents Sea; however, intermittent fisheries for polar cod have also existed in the past. NSS herring uses the Barents Sea as a nursery area during the first 2 to $3 \mathrm{yr}$ of life, before migrating to the Norwegian Sea where commercial exploitation takes place (however, historically, there have also been significant herring fisheries in the Barents Sea).

We isolated some candidate mechanisms explaining why the importance of recruitment for population dynamics changes. Transient elasticity shows how much a transient change in a vital rate (survival or recruitment) influences the population growth, and through our GAM analysis, which variable is affecting this influence. Note that following the methods used, if the elasticity to recruitment increases, the elasticity to survival decreases, and vice versa. However, transient elasticity does not tell us how much 
the population is actually changing, but it helps us to understand the processes underlying these changes. In our study, the pre-eminent factor is the negative association between the generation time $\mu$ and the transient elasticity to recruitment, confirming a previous study conducted on other data for gadoids only (Durant et al. 2013). This emphasises how the elasticity to recruitment can be affected by a long-term deterioration of the age structure of the population (Rouyer et al. 2011, Hidalgo et al. 2012). In other words, the reduction in generation time $\mu$ may trigger an increase in the relative contribution of recruitment to population growth. This result makes sense since stocks with shorter generation times usually respond more strongly to changes in recruitment (Fig. 3A). Our results indicate that this effect is strong at both an interspecific (Fig. 3A,E) and intraspecific level (Fig. 3A), with $\mu$ being an explanatory variable for all GAM models (Fig. 2, Table 2). Thus, this effect is clearly not species-specific but can be induced by juvenation of a stock (e.g. by fishing). For example, the generation time for cod, haddock and herring is not constant over time (Fig. 1), explaining much of the increase in recruitment contribution to the population growth (Fig. 2, Table 2).

Fishing is size selective, and can induce genetic adaptations in highly fished fish stocks (Jørgensen et al. 2007). In particular, fisheries targeting the bigger, older and highly reproductive fish may lead to an earlier maturation at a smaller size. For our analysis, this means a change in the reproductive value in the transition matrices following a reduction of the generation time (Fig. 1). However, while the biggest (monotonic) change in generation time occurred in NEA cod, the effect of generation time on sensitivity is in fact stronger in the case of NEA haddock, where generation time has remained relatively constant (or slightly increased) over the years (Fig. 1, Table 2). Climate has been shown to affect length-at-age with potential demographic consequences (Rogers et al. 2011). Many ecological processes, such as survival, depend on size or growth rate. A change in the thermal environment can affect recruitment (Beaugrand et al. 2003) and/or survival at young ages (Sogard 1997) and thus lead to a change in the matrices.

It is noteworthy that the transient elasticity with respect to recruitment is generally small compared to the elasticity to survival (given that $\boldsymbol{e}_{\text {recruitment }}=1-$

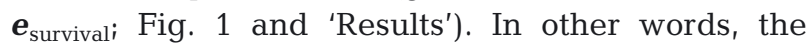
dynamics of the 5 stocks in general depend more on survival than recruitment, which is also true for relatively short-lived species such as capelin, but sometimes more on the recruitment processes during re- covery periods after a population crash (the data includes 1 major stock collapse in the case of herring and 3 collapses in the case of capelin).

The strong negative association between the generation time $\mu$ and the elasticity to recruitment (Figs. 2 \& 3A) was to be expected from a purely mathematical standpoint (Stearns 1992, Oli \& Dobson 2003). The power of our analyses lies in taking generation time into account when exploring the effect of the 2 other processes that may affect elasticity, namely fishing pressure (as described by fishing mortality, $F$ ) and the environmental conditions (as described by sea temperature, ST, and the winter North Atlantic Oscillation, wNAO).

We found that the present fishing pressure does not affect the contribution of recruitment to population growth (Fig. 3B), with the exception of a positive effect for cod (Table 2). However, there is a strong association between generation time and elasticity to recruitment, in accordance with the results of Rouyer et al. (2011), who suggested that the fluctuations in age-truncated stocks are more tightly linked to the environment. However, note that the indirect effect of fishing through age truncation has already been taken into account in the statistical equation (by including generation time as a variable). The reason that the elasticity of cod varies with both generation time and fishing may be that generation time is an imperfect measurement of life history, which has several components (e.g. age at first maturation, adult mortality).

For 4 of the 5 studied species, we found that warmer conditions (either measured directly through the Kola transect temperature or indicated by high NAO) increased the dependence of population growth on recruitment variations (Ottersen et al. 2006). In a previous study, the age truncation of fish stocks was found to be associated with an increasing influence of temperature on population growth rate, at the same time as becoming increasingly sensitive to recruitment variations (Rouyer et al. 2011). Thus, age-truncated populations, being more sensitive to climate variability, become more difficult to manage due to the unpredictable future environmental variations. Following this prediction, the studied stocks should still be manageable despite climate change, as this study shows that the elasticity to recruitment is low compared to the elasticity to survival for most of the stocks (Fig. 1); thus, fishing mortality has a dominant effect on overall population development.

One particular case is capelin, where no model was found to explain the elasticity to recruitment. This stock exhibits huge variation in abundance, with 3 
collapses (mid-1980s, early 1990s and early 2000s) due to recruitment failure, and is highly affected by trophic interactions with other Barents Sea species such as herring and cod (Hjermann et al. 2010). Reciprocally, the fluctuations in capelin abundance in the Barents Sea affect its predators (Durant et al. 2014). The time series can be roughly divided in 2 , with a first period prior to 1985 when the population was intensively harvested and a second period when it was not. As shown in Fig. 1, this corresponds to a first period where the abundance and generation time decreased, and a second period with a more stable (but relatively low) generation time and a highly fluctuating abundance. However, the elasticity appears to fluctuate around the same level in both periods. We were not able to explain how the capelin elasticity to recruitment varied between years, even when we tried to extend our modelling to top-down control by including the abundance of cod and herring. However, Stige et al. (2010) have shown that the dynamics of the capelin stock in the Barents Sea could be explained by a bottom-up effect in association with a top-down effect. Taking into account both top-down and bottom-up effects was beyond the scope of this paper but may explain our lack of success in obtaining a model.

The data we used differs between the 5 stocks we analysed. For 3 stocks, population estimates are based on virtual population analysis (VPA), which combines data on the age composition of commercial catches with abundance indices from scientific surveys. For the remaining 2 species, the populations are estimated based on scientific surveys (acoustic surveys combined with trawl sampling) only. The most important difference between these 2 types of data is that VPA assumes that natural mortality is known; it is either set to be constant (herring), or it is estimated on a yearly basis, based on data of predator stomach contents (cod and haddock). In the first case, the variation in relative strength of weak and strong year classes is underestimated if the true natural mortality varies with year class strength (Ulltang 1977). While this probably affects our results to some degree, they appear robust, which leads us to believe that the assessment used does not affect our main conclusions.

The results of this study follow previous work on gadoid fishes across several regions (Durant et al. 2013). The main differ- ence to the modelling approaches of Durant et al. (2013) is that we have added an auto-correlation term (abundance $t-1$ ) that indicates whether a densitydependent effect is at play. To compare the 2 sets of models, we calculated the relative importance of the contribution of the selected explanatory variables (Table 3). For our models, the autocorrelation term can explain $20 \%$ (NEA cod) to $67 \%$ (herring) of the variability in the elasticity, showing the importance of this variable. That being said, while generation time enters most models, it has a very different level of contribution depending on the stock considered, ranging from $5 \%$ (polar cod) to $69 \%$ (Balearic Islands hake Merluccius merluccius). This variation is, for the most part, a mirror image of the contribution of sea temperature, which ranges from $1 \%$ (Gulf of Alaska pollock) to $64 \%$ (northern Atlantic hake). There was no clear pattern differentiating gadoids from other species, but a common feature was that the species with a high contribution of generation time to the sensitivity of population growth to recruitment had a low climatic contribution, and vice versa. No species were equally affected by change in generation time and temperature. These results are to be read in light of the results of Rouyer et al. (2011), which indicate that the sensitivity to climate is related to the health of the ecosystem.

Table 3. Relative importance of explanatory variables estimated by proportional marginal variance decomposition (sum equal to 1). The quantification of the contribution of an individual explanatory variable to a multiple regression model explaining the variation of the transient elasticity was studied using the package 'relaimpo' (Grömping 2006) using the 'proportional marginal variance decomposition' (pmvd) (Feldman 2005). Northeast Arctic (NEA) cod Gadus morhua, Norwegian spring spawning (NSS) herring Clupea harengus, NEA haddock Melanogrammus aeglefinus and polar cod Boreogadus saida are from this study. Eastern Bering Sea (EBS) and Gulf of Alaska (GOA) pollock Theragra chalcogramma stocks, North Sea (NS) cod stock, northern Atlantic (NA), southern Atlantic (SA) and Balearic Islands (BI) hake Merluccius merluccius stocks are from Durant et al. (2013)

\begin{tabular}{|lccccc|}
\hline Species & $\begin{array}{c}\text { Generation } \\
\text { time }\end{array}$ & $\begin{array}{c}\text { Fishing } \\
\text { mortality }\end{array}$ & $\begin{array}{c}\text { Climate } \\
\text { index }\end{array}$ & $\begin{array}{c}\text { Sea } \\
\text { temperature }\end{array}$ & Abundance \\
\hline NEA cod & 0.50 & 0.15 & & 0.15 & 0.20 \\
NSS herring & 0.27 & & 0.06 & & 0.67 \\
NEA haddock & 0.36 & & & 0.38 & 0.26 \\
Polar cod & 0.05 & & 0.54 & 0.41 & \\
& & & & & \\
Models from Durant et al. (2013) & & & \\
SA hake & 0.68 & & 0.14 & 0.18 & \\
NA hake & 0.16 & & & 0.20 and 0.64 & \\
BI hake & 0.69 & & & 0.31 & \\
NS cod & & 0.33 & 0.35 & 0.32 & \\
EBS pollock & & 0.24 & 0.54 & 0.22 & \\
GOA pollock & 0.19 & & 0.30 & 0.01 and 0.50 & \\
\end{tabular}


In summary, our findings confirm the results of a previous study conducted on 7 stocks of gadoid populations (Durant et al. 2013): the elasticity of population growth to recruitment is primarily affected by long-term changes in age structure of the population, typically caused by fishing, while there is little or no additional effect of the ongoing fishing pressure. Warmer conditions increase the elasticity to recruitment of the population, even after generation time has been taken into account. Thus, while future global warming may result in generally more productive Barents Sea fish stocks (Stenevik \& Sundby 2007), it will make them more sensitive to climate fluctuations and less sensitive to fishing pressure. The latter will make the stock more difficult to manage by adjusting the fishing pressure (Rouyer et al. 2011). This may call for stock management strategies that are more flexible, taking into account natural fluctuations. However, for most of the stocks studied here, populations have low elasticity to recruitment, meaning that management, not climate, is to blame if the stock declines. More than ever, taking recruitment variation into account is essential for stock management (Hjort 1914, Houde 2008).

Acknowledgements. J.M.D. acknowledges the support from the Research Council of Norway through the SUSTAIN project (grant no. 244647/E10) and through the MARmaED project. MARmaED received funding from the European Union's Horizon 2020 research and innovation programme under grant agreement no. 675997. Responsibility for the information and views set out in this publication lies entirely with the authors. We thank Rebecca E. Holt for her editorial help and 3 anonymous reviewers for constructive and valuable comments to earlier versions of this paper.

\section{LITERATURE CITED}

Beaugrand G, Brander KM, Lindley JA, Souissi S, Reid PR (2003) Plankton effect on cod recruitment in the North Sea. Nature 426:661-664

Caswell H (2001) Matrix population models: construction, analysis, and interpretation, 2nd edn. Sinauer Associates, Sunderland, MA

Caswell H (2007) Sensitivity analysis of transient population dynamics. Ecol Lett 10:1-15

Cole LC (1954) The population consequences of life history phenomena. Q Rev Biol 29:103-137

* de Kroon H, Plaisier A, van Groenendael J, Caswell H (1986) Elasticity: the relative contribution of demographic parameters to population growth rate. Ecology 67:1427-1431

Drinkwater K, Hunt GL, Lehodey P, Lluch-Cota S and others (2010) Climate forcing on marine ecosystems. In: Barange M, Field JG, Harris RP, Hofmann EE, Perry RI, Werner F (eds) Marine ecosystems and global change. Oxford University Press, Oxford, p 11-39

Durant JM, Hidalgo M, Rouyer T, Hjermann D $\varnothing$ and others (2013) Population growth across heterogeneous environ- ments: effects of harvesting and age structure. Mar Ecol Prog Ser 480:277-287

* Durant JM, Skern-Mauritzen M, Krasnov YV, Nikolaeva NG, Lindstrom U, Dolgov A (2014) Temporal dynamics of top predators interactions in the Barents Sea. PLOS ONE 9:e110933

Eriksen E (ed) (2012) Survey report from the joint Norwegian/ Russian ecosystem Survey in the Barents Sea, AugustOctober 2012, Vol IMR/PINRO Joint Report Series, No. $2 / 2012$

Feldman B (2005) Relative importance and value. Unpublished manuscript (Version 1.1, March 19 2005). Available online at www.prismanalytics.com/docs/Relative Importance050319.pdf

Grömping U (2006) Relative importance for linear regression in R: the package relaimpo. J Stat Softw 17:1-27

*Hamre J (1994) Biodiversity and exploitation of the main fish stocks in the Norwegian-Barents Sea ecosystem. Biodivers Conserv 3:473-492

Hidalgo M, Rouyer T, Bartolino V, Cerviño S and others (2012) Context-dependent interplays between truncated demographies and climate variation shape the population growth rate of a harvested species. Ecography 35:637-649

Hjermann DØ, Stenseth NC, Ottersen G (2004) Indirect climatic forcing of the Barents Sea capelin: a cohort effect. Mar Ecol Prog Ser 273:229-238

* Hjermann DØ, Bogstad B, Dingsør GE, Gjøsæter H, Ottersen G, Eikeset AM, Stenseth NC (2010) Trophic interactions affecting a key ecosystem component: a multi-stage analysis of the recruitment of the Barents Sea capelin (Mallotus villosus). Can J Fish Aquat Sci 67:1363-1375

Hjort J (1914) Fluctuations in the great fisheries of Northern Europe viewed in the light of biological research. Rapp P-V Reun Cons Int Explor Mer 20:1-228

*Houde ED (2008) Emerging from Hjort's shadow. J Northwest Atl Fish Sci 41:53-70

* Hurrell JW (1995) Decadal trends in the North Atlantic Oscillation: regional temperatures and precipitations. Science 269:676-679

* Hurrell JW, Deser C (2009) North Atlantic climate variability: The role of the North Atlantic Oscillation. J Mar Syst 78: 28-41

ICES (2007) Report of the Working Group on Northern Pelagic and Blue Whiting Fisheries (WGNPBW), 27 August to 1 September 2007, Vigo, Spain. ICES CM 2007/ACFM 29

ICES (2013a) Report of the Arctic Fisheries Working Group (AFWG) 18 to 24 April 2013, ICES Headquarters, Copenhagen. ICES CM 2013/ACOM: 05

ICES (2013b) Report of the Working Group on Widely Distributed Stocks (WGWIDE), 27 August to 2 September 2013, ICES Headquarters, Copenhagen, Denmark. ICES CM 2013/ACOM: 15

Jakobsen T, Ozhigin VK (eds) (2011) The Barents Sea: ecosystem, resources, management. Half a century of RussianNorwegian cooperation. Tapir Academic Press, Trondheim

Jørgensen C, Enberg K, Dunlop ES, Arlinghaus R and others (2007) Ecology: managing evolving fish stocks. Science 318:1247-1248

Lambert Y (2013) Long-term changes in life history characteristics and reproductive potential of northern Gulf of St. Lawrence cod (Gadus morhua) and consequences for the stock productivity. Fish Res 138:5-13

Lassen H, Medley P (2001) Virtual population analysis. A practical manual for stock assessment. FAO Fish Tech Pap 400. FAO, Rome 
Leggett WC, Deblois E (1994) Recruitment in marine fishes: Is it regulated by starvation and predation in the egg and larval stages? Neth J Sea Res 32:119-134

Leslie PH (1945) On the use of matrices in certain population mathematics. Biometrika 33:183-212

Marshall CT, McAdam BJ (2007) Integrated perspectives on genetic and environmental effects on maturation can reduce potential for errors of inference. Mar Ecol Prog Ser 335:301-310

Murphy GI (1968) Pattern in life history and the environment. Am Nat 102:391-403

Oli MK, Dobson FS (2003) The relative importance of lifehistory variables to population growth rate in mammals: Cole's prediction revisited. Am Nat 161:422-440

Ottersen G (2008) Pronounced long-term juvenation in the spawning stock of Arcto-Norwegian cod (Gadus morhua) and possible consequences for recruitment. Can J Fish Aquat Sci 65:523-534

Ottersen G, Hjermann DO, Stenseth NC (2006) Changes in spawning stock structure strengthen the link between climate and recruitment in a heavily fished cod (Gadus morhua) stock. Fish Oceanogr 15:230-243

* Ottersen G, Stige LC, Durant JM, Chan KS, Rouyer TA, Drinkwater KF, Stenseth NC (2013) Temporal shifts in recruitment dynamics of North Atlantic fish stocks: effects of spawning stock and temperature. Mar Ecol Prog Ser 480:205-225

R Development Core Team (2011) R: a language and environment for statistical computing. R Foundation for Statistical Computing, Vienna. www.R-project.org/

Rogers LA, Stige LC, Olsen EM, Knutsen H, Chan KS, Stenseth NC (2011) Climate and population density drive changes in cod body size throughout a century on the Norwegian coast. Proc Natl Acad Sci USA 108:1961-1966

Rouyer T, Ottersen G, Durant JM, Hidalgo M and others (2011) Shifting dynamic forces in fish stock fluctuations triggered by age truncation? Glob Change Biol 17: 3046-3057

Editorial responsibility: Katherine Richardson, Copenhagen, Denmark
Schaffer WM (1974) Optimal reproductive effort in fluctuating environments. Am Nat 108:783-790

Shepherd JG, Pope JG (2002) Dynamic pool models. I. Interpreting the past using virtual population analysis. In: Hart PJB, Reynolds JD (eds) Handbook of fish biology and fisheries. Vol 2, fisheries. Blackwell Science, Oxford, p $127-136$

Sogard SM (1997) Size-selective mortality in the juvenile stage of teleost fishes: a review. Bull Mar Sci 60:1129-1157

Stearns SC (1992) The evolution of life histories. Oxford University Press, Oxford

Stenevik EK, Sundby S (2007) Impacts of climate change on commercial fish stocks in Norwegian waters. Mar Policy 31:19-31

Stige LC, Ottersen G, Dalpadado P, Chan KS and others (2010) Direct and indirect climate forcing in a multi-species marine system. Proc R Soc Lond B Biol Sci 277: 3411-3420

Tereschenko VV (1996) Seasonal and year-to-year variations of temperature and salinity along the Kola meridian transect. ICES CM 1996/C: 11

* Ulltang Ø (1977) Sources of errors in and limitations of Virtual Population Analysis (Cohort Analysis). ICES J Mar Sci 37:249-260

Wood SN (2006) Generalized additive models: an introduction with R. Chapman \& Hall/CRC, Boca Raton, FL

* Wood SN, Augustin NH (2002) GAMs with integrated model selection using penalized regression splines and applications to environmental modelling. Ecol Modell 157: 157-177

Wright PJ (2014) Are there useful life history indicators of stock recovery rate in gadoids? ICES J Mar Sci 71: 1393-1406

*Wright P, Palmer SF, Marshall CT (2014) Maturation shifts in a temperate marine fish population cannot be explained by simulated changes in temperaturedependent growth and maturity. Mar Biol 161: 2781-2790

Submitted: June 6, 2016; Accepted: May 23, 2017 Proofs received from author(s): July 28, 2017 